\title{
QUESTÕES AMBIENTAIS: SUSTENTABILIDADE E CURRÍCULO ABORDAGENS PRÁTICAS E TEÓRICAS
}

\author{
Maria Geralda de Miranda ${ }^{1}$ \\ Alexandre de Jesus Pereira ${ }^{2}$
}

\begin{abstract}
Resumo
O presente artigo tem como objetivo analisar a importância de trabalhar a sustentabilidade para uma formação cidadã e compreender a sua contribuição para o currículo. Partimos do pressuposto de que é importante estarmos cada vez mais conscientes da necessidade de construir um futuro sustentável na nossa sociedade. A sustentabilidade é um tema que atravessa muitas as áreas como é o caso da Educação Ambiental. Nesse sentido, a EA pode e deve ser entendida como um tema transversal e interdisciplinar, ou seja, ela deve ser integrada a um pensar complexo (MORIN, 2009). A existência de um pensar complexo encaminhará o viés econômico e político da atual sociedade para o contexto da sustentabilidade. Desse modo, discutiremos o significado de sustentabilidade e a necessidade de incluí-la como um eixo que norteie as experiências e práticas curriculares para que se possa obter um currículo que auxilie na formação de cidadãos mais críticos e conscientes no que diz respeito às questões ambientais.
\end{abstract}

Palavras-chave: Meio Ambiente; Educação Ambiental;currículo

\begin{abstract}
This article aims to analyze the importance of working sustainability for a citizen education and to understand its contribution to the curriculum. We start from the assumption that it is important to be increasingly aware of the need to build a sustainable future in our society. Sustainability is a theme that crosses many areas such as the case of Environmental Education. In this sense, EA can and should be understood as a transversal and interdisciplinary theme, that is, it must be integrated into a complex thinking (MORIN, 2009). The existence of a complex thinking will lead the economic and political bias of the current society to the context of sustainability. In this way, we will discuss the meaning of sustainability and the need to include it as an axis that guides curricular experiences and practices so that a curriculum can be obtained that helps to train citizens who are more critical and conscious about environmental issues.
\end{abstract}

Keywords: Environment; Environmental Education; curriculum

\footnotetext{
${ }^{1}$ Doutora em Letras pela UFF, Coordenadora do Curso de Letras do Centro Universitário Augusto Motta UNISUAM e Líder do LAMEL (Laboratório Multidisciplinar de Estudos da Linguagem)

${ }^{2}$ Mestre em Desenvolvimento Local do Centro Universitário Augusto Motta - UNISUAM
} 


\section{Introdução}

A educação pode desempenhar um papel fundamental na formação do indivíduo desde que trabalhada de maneira coerente e precisa. Para esse fim, compreender as orientações curriculares para o ensino acerca de questões que tratam da sustentabilidade é de extrema importância. A educação para a sustentabilidade implica uma nova perspectiva e orientação para a prática pedagógica, proporcionando situações de aprendizagem que favorecem experiências práticas ao educando em ações colaborativas e na resolução de problemas de nível local, regional e global. Isso requer uma nova maneira de pensar o papel do ensinoaprendizagem que, certamente, poderá influenciar a formação de alunos e professores.

Destarte, o objetivo deste estudo é analisar a importância de trabalhar a sustentabilidade para uma formação cidadã e compreender a sua contribuição para o currículo. Para tanto, na primeira parte buscaremos definir a noção de sustentabilidade relacionando-a as ações e atividades humanas que objetivam suprir as necessidades contemporâneas dos indivíduos. A seguir trataremos de apontar a importância da sustentabilidade na formação do cidadão. Em seqüência, faremos uma breve análise sobre os desafios para uma educação sustentável. Posteriormente, faremos uma reflexão sobre currículo e sustentabilidade e suas relações frente às diversidades socioculturais.

\section{Sustentabilidade, formação e sua contribuição para o currículo}

Segundo o Dicionário Aurélio, sustentabilidade é a qualidade que algo tem em se manter relativamente constante, ou estável, por um longo período. Assim, torna-se evidente que desenvolvimento sustentável acontece quando o indivíduo retira o necessário da natureza, mas assegura a possibilidade de vida das futuras gerações. De acordo com Bacha (2010), a definição de sustentabilidade mais difundida é a da Comissão Brundtland, Word Commission on Environment and Development de 1987, segundo a qual o desenvolvimento sustentável é aquele que atende às necessidades das gerações presentes, sem comprometer a possibilidade das gerações futuras atenderem suas próprias necessidades. Essa definição evidencia um dos princípios básicos de sustentabilidade, a visão de longo prazo, uma vez que os interesses das futuras gerações devem ser considerados.

Para Goldsmith (1972), uma sociedade pode ser considerada sustentável quando todos os seus propósitos e intenções podem ser atendidos de forma indefinida, garantindo plena 
satisfação aos seus membros. Pronk (1992) destaca o papel do crescimento econômico na sustentabilidade. Para esse autor, o desenvolvimento é sustentável quando o crescimento econômico traz justiça e oportunidades para todos os seres humanos do planeta, sem privilégio de algumas espécies, sem destruir os recursos naturais finitos e sem ultrapassar a capacidade de carga do sistema.

Sustentabilidade é uma noção utilizada para definir ações e atividades humanas que objetivam suprir as necessidades contemporâneas dos seres humanos, sem comprometer o futuro das gerações. Ou seja, a sustentabilidade se relaciona diretamente com o desenvolvimento material e econômico sem agredir o meio ambiente, utilizando os recursos naturais de maneira inteligente para que eles se mantenham no futuro. A partir desses parâmetros, a humanidade pode garantir o desenvolvimento sustentável (MORIN 2000).

De acordo com Moreira e Candau (2006), o currículo é um objeto de reflexão variada, que se organiza de acordo com os sujeitos e o espaço que o envolve. Os autores firmam que as demandas curriculares são marcadas pelos debates sobre conhecimento, verdade, poder e identidade.

Silva (1995) indica que o conhecimento, o currículo e a cultura são produzidos por meio das relações sociais e principalmente pelas práticas de experiências concretas produzidas pelos sujeitos, podendo ser percebida como uma atividade de aspecto político e social.

Todas essas questões ambientais trazem consigo um amplo desafio político, ético e econômico, que deve ser trabalhado de maneira educativa, possibilitando práticas em que os indivíduos compreendam a importância dessa temática

Segundo Grandisoli (2011).

A sustentabilidade tem ganhado espaço dentro da realidade de algumas poucas escolas no Brasil. As restrições do currículo atual, a falta de preparo específico e a grande amplitude do tema talvez sejam apenas alguns dos motivos por trás desse fato.

Assim, o tema vai ganhando relevância nas instituições educacionais, e é preciso que o currículo também se adapte à realidade atual frente às perspectivas das práticas educacionais contemporâneas.

De acordo com Morin (2000) a humanidade vem cada vez mais estabelecendo uma relação predatória com a natureza devido ao modelo consumista que resulta do modo de produção capitalista e, devido a esse modelo de vida, a humanidade se aproxima apressadamente de um cenário de calamidade ambiental. A relação ensino/aprendizagem deve RPI Revista de Pesquisa Interdisciplinar, Cajazeiras, v. 1, n. 1, 47-57, jan/jul. de 2017. 
se preocupar em ensinar como cuidar do mundo e do coletivo de forma pertinente e eficaz, conscientizando não só os educandos, mas também todo o corpo docente das instituições de ensino, os profissionais que nelas trabalham a comunidade, a sociedade e o mundo. Somente por meio da educação será possível construir comportamentos e hábitos direcionados a sustentabilidade. Isso só será possível através da reestruturação do currículo que deverá ser trabalhado de forma integrada aos conhecimentos e experiências escolares.

\section{A importância da sustentabilidade na formação do cidadão}

Antunes (2002) afirma que o paradigma da sustentabilidade em sua relação com a economia, o meio ambiente, a sociedade e a cultura deve ser entendido para além do tratamento da produção de bens e serviços. Essa relação se baseia na construção de um sujeito que seja capaz de relacionar produção, meio ambiente, sociedade e desenvolvimento de forma responsável e equilibrada. Para isso, é necessário articular no currículo escolar os temas complexos e esses, por sua vez, interdisciplinares com os conteúdos, intentando à formação humanizada do sujeito, contemplando o mundo na totalidade e ele como parte integrante dessa totalidade que compõe o universo.

Morin (1991) chama atenção para a complexidade do homem e do mundo e como os mesmos estão interligados por meio das partes que estão no todo e todo que está nas partes. Em cada uma delas estão presentes qualidades próprias e individuais, mas a totalidade das partes está presente no todo de forma real e completa, uma espécie de rede relacional e interdependente, em que nada se isola no universo, tudo está em interação. Dessa forma, o individuo, ao mesmo tempo em que é autônomo, se torna dependente em uma circularidade que o singulariza e distingue simultaneamente. Como o termo latino indica: "Complexus - o que é tecido junto" (MORIN 1991, p. 44).

O paradigma da complexidade, em termos de educação ambiental, traz em seu âmago a noção de interdisciplinaridade apontando, não para uma radicalização unilateral em defesa de seus princípios, mas apontando para um caminho do meio, para uma espécie de terceira via (Vasconcelos, 2002) que certamente valorizará a multidimensionalidade e a própria complexidade dos fenômenos que envolvem o campo do ambientalismo, bem como o campo sócio-cultural e econômico, para atingir a emancipação do cidadão e, conseqüentemente, da sociedade como um todo. 
Morin (1991) também faz abordagens acerca do o homo complexus que é responsável pelo modo de organização que se constrói na partilha e solidariedade de uma forma de pensamento que liberta, porque é criativo, artístico, político, educacional e ético. A este respeito Layrargues mostra que:

Pensar de forma complexa implica fazer com que o agir seja consciente, no sentido de se saber qual o terreno em que nos movemos, o alcance de determinada ação, apresentando coerência entre o que se quer, a base teórica da qual se parte, onde se quer chegar e quem se beneficia com o processo. Qual enquadramento, pano de fundo ou leitura da realidade há (2004, p.12).

Portanto, ao considerarmos a questão da sobrevivência dos seres humanos não restará dúvidas de que o melhor caminho é conceber a comunicação entre as diversas áreas do saber e compreender ordem, desordem e organização como etapas importantes e necessárias de um processo que culmina na organização de todos os sistemas vivos (MORIN 1991).

Toda a problemática da sustentabilidade traz consigo um imenso desafio ético/político e econômico, que pode e deve ser trabalhado de maneira educativa, possibilitando ações em que o indivíduo compreenda a importância dessa temática. Para isso, é necessário que o currículo seja pensado de forma ampla e complexa, considerando o homem no mundo, sendo o mundo a sobrevivência do homem e o homem responsável por manter o mundo e a sua geração, buscando um equilíbrio indissociável e subjetivo.

É possível observar que as tecnologias desenvolvidas pelo homem são transformadas e utilizadas pelo próprio ser humano para causar destruição ameaçando espécies inteiras. Faz-se necessária a conscientização urgente, não para impedir-lhe nos seus avanços e desenvolvimento, que fazem parte da própria constituição humana, mas realmente educá-lo na criticidade, construindo junto aos educandos uma ideologia que possa orientar o pensamento reflexivo das suas práticas, criticando a si próprio e os que detêm o poder, como explicita Freire (1959, p. 28) "é preciso dar-lhe uma ideologia do desenvolvimento".

O capitalismo seria o principal vilão de todo degradação, no entanto nós o criamos ou permitimos que fosse criado, e o pior, nós alimentamos todos os dias a sua monstruosa necessidade de poder e devastação. Através da nossa consciência ingênua, cresce o desejo de oprimir, de causar desigualdades sociais, miséria, morte cultural, histórias, identidades, e, sobretudo, as nossas riquezas naturais. Essa alienação, denominada de consciência ingênua por Paulo Freire (1959), se manifesta no consumismo alimentado pela máquina da multimídia que nos fascina e nos corrompe nos conduzido ao extermínio. 
Gadotti (2003) também aborda o tema "Educar para uma vida saudável". Ele aponta a importância de educar a humanidade no presente para sua própria existência futura, alertando para uma mudança de postura diante do sistema capitalista que é nutrido pelo consumismo. Visando diminuir as desigualdades sociais através da educação, o educador pode promover a educação ambiental, social e cultural nas escolas, empresas e em todas as comunidades, protegendo a biodiversidade e a sustentabilidade da sociedade e também do planeta, conscientizando as pessoas da importância das fontes de energia naturais, como a opção por produtos recicláveis.

Portanto, é preciso refletir sobre os desafios da sustentabilidade em suas diversas dimensões ambientais, econômicas e sociais. As pesquisas científicas e tecnológicas, os intercâmbios científicos e o uso generalizado e aberto dos dados e resultados científicos são fatores essenciais para enfrentar estes desafios, tendo em vista os limites naturais do planeta e a necessidade de estruturas socioeconômicas renovadas. Contudo, a educação de qualidade é um elemento indispensável para possibilitar uma formação cidadã adequada para o desenvolvimento sustentável (MORIN 2000).

\section{O currículo diante e os desafios para uma educação sustentável}

Morin (2000) afirma que as pessoas precisam compreender o quanto é importante ter uma vida sustentável, ele também indica que somente através de uma educação que contemple essa necessidade, desde a primeira infância, é que elas poderão compreender essa realidade. $\mathrm{O}$ autor nos apresenta esta perspectiva

\footnotetext{
Neste momento, um destino comum para todos os seres humanos. O crescimento da ameaça letal se expande em vez de diminuir: a ameaça nuclear, a ameaça ecológica, a degradação da vida planetária. Ainda que haja uma tomada de consciência de todos esses problemas, ela é tímida e não conduziu ainda a nenhuma decisão efetiva. Por isso, faz-se urgente a construção de uma consciência planetária (MORIN, 2000, p. 10).
}

Essa consciência precisa ser compreendida para que o cuidado com o nosso planeta seja algo natural no cotidiano de nossos jovens. Um currículo em que a sustentabilidade esteja inserida no programa pedagógico, que faça parte da vida dos alunos é de fundamental importância (MORIN, 2000).

RPI Revista de Pesquisa Interdisciplinar, Cajazeiras, v. 1, n. 1, 47-57, jan/jul. de 2017. 
Morin afirma que (2000) o principal objetivo da Sustentabilidade quando inserida no currículo é o de integrar os princípios, os valores e as práticas do desenvolvimento sustentável a todos os aspectos da educação e da aprendizagem.

De acordo com Santos (2002, p. 273)

\begin{abstract}
Aos instrumentos do ambientalismo - como o licenciamento e planejamento ambiental, tecnologias de conservação, auditorias ambientais, estudo e relatório de impacto ambiental, legislação, e outras devem somar-se a educação e a escola, como importantes mecanismos de socialização (e aqui, devesse considerar tanto o currículo oficial como o currículo oculto, como mecanismos de instauração de crenças e de práticas). A educação para a mudança impõe, contudo, como condição prévia, uma mudança da educação.
\end{abstract}

A educação para a mudança tem que ter início não só no reduto familiar, mas também nas escolas, representando assim uma nova visão da educação capaz de ajudar pessoas de todas as idades a entenderem melhor o mundo em que vivem tratando da complexidade de problemas tais como pobreza, consumo predatório, degradação ambiental, deterioração urbana, saúde, conflitos e violação dos direitos humanos, que hoje ameaçam nosso futuro.

\title{
Os desafios para uma educação sustentável.
}

De acordo com os PCN's (Parâmetros Curriculares Nacionais), a diversidade corresponde às características étnicas e culturais dos diferentes grupos sociais. Partindo do quesito sociocultural, a diversidade pode ser representada como a construção cultural e social das diferenças. Essas diferenças são construídas pelos cidadãos no decorrer de suas vidas, nos seus processos de adaptações ao meio e no contexto das relações sociais. Ao falarmos das diversidades socioculturais, não podemos esquecer que elas se dão em conjunto com os processos de identidade dos seres humanos. A teoria da Complexidade organizada por Morin (2000, p. 57) nos dá uma ideia dessa complexidade:

O ser humano é ao mesmo tempo singular e múltiplo. Dissemos que todo ser humano, tal como o ponto de um holograma, traz em si o cosmo. Devemos ver também que todo ser, mesmo aquele fechado na mais banal das vidas, constitui ele próprio um cosmo. Traz em si multiplicidades interiores, personalidades virtuais, uma infinidade de personagens quiméricos, uma poliexistência no real e no imaginário, no sono e na vigília, na obediência e na

RPI Revista de Pesquisa Interdisciplinar, Cajazeiras, v. 1, n. 1, 47-57, jan/jul. de 2017. 
transgressão, no ostensivo e no secreto, balbucios embrionários em suas cavidades e profundezas insondáveis. Cada qual contém em si galáxias de sonhos e de fantasmas, impulsos de desejos e amores insatisfeitos, abismos de desgraças, imensidões de indiferença gélida, queimações de astro em fogo, acessos de ódio, desregramentos,lampejos de lucidez, tormentas dementes.

Morin (2000) afirma que os seres humanos devem reconhecer-se em sua humanidade comum e, ao mesmo tempo, reconhecer a diversidade complexa no mundo no qual está inserido. A educação, numa visão geral, é um processo que engloba a condição humana, por isso está presente em toda sociedade. Ao longo da nossa vida, realizamos diversas aprendizagens. Essas aprendizagens são marcadas pela interação entre o ser humano e o meio. E através dessa interação é que construímos nossos conhecimentos e valores. Sendo assim, o desenvolvimento das práticas culturais é essencial para a realização do humano.

De acordo com Quaresma (2004, p. 16), “o currículo é compreendido como uma sequencia de experiências vivenciadas pelo educando, experiências programadas pelo educador as quais devem ter objetivos muito claros". Dessa forma, o currículo assume a tendência de ficar cada vez mais próximo das diversidades sociais e culturais, pois as experiências das diversidades experienciadas fazem parte dos processos de socialização e de humanização.

A cultura é constituída pelo conjunto dos saberes, fazeres, regras, normas, proibições, estratégias, crenças, idéias, valores, mitos, que se transmite de geração em geração, se reproduz em cada indivíduo, controla a existência da sociedade e mantém a complexidade psicológica e social. Não há sociedade humana, arcaica ou moderna, desprovida de cultura, mas cada cultura é singular. (MORIN, 2000, p. 56).

Vivemos, assim, no contexto da diversidade cultural e esta deve estar presente no currículo. A cultura deve ser percebida como um meio que dirige as experiências e práticas pedagógicas curriculares, pois ela garante a efetuação do individuo e, consequentemente, da sociedade (QUARESMA, 2004).

Um currículo que respeite as diversidades deve ser bem pensado e elaborado. As discussões sobre sustentabilidade e diversidade auxiliam na produção de um bom currículo e antecipa uma nova estrutura de escola voltada para uma concepção de educação que não só desenvolva habilidades e competências, mas também para formar cidadãos com capacidade de mudar sua realidade (QUARESMA, 2004).

Desse modo, uma melhor adaptação curricular, que contemple a diversidade e a sustentabilidade possibilitará que o indivíduo se sinta preparado, ao sair das escolas, para RPI Revista de Pesquisa Interdisciplinar, Cajazeiras, v. 1, n. 1, 47-57, jan/jul. de 2017. 
enfrentar o mundo em permanente transformação e participar dessa transformação de maneira responsável. Por isso não podemos deixar de trabalhar com elas nas escolas e incluí-las nos currículos.

\section{Considerações finais}

Não foi nosso propósito indicar soluções ou encontrar um novo modelo de currículo, mas sim problematizar a temática, visando despertar os profissionais da educação a abrirem os olhos e refletirem sobre sua prática. Ao abordarmos um assunto de tamanha relevância como a sustentabilidade, nos apoiamos em teorias que ampliam a perspectiva dessa questão, indo além da educação ambiental, voltando assim a sustentabilidade para as práticas de educação para o bem estar de nossas vidas.

Acreditamos que a reestruturação do currículo, de maneira a contemplar uma educação direcionada às práticas de sustentabilidade, possa atingir a nova perspectiva de alunos que nos espera.

Sabemos que exercemos nossas atividades em um modelo de escola no qual o tradicionalismo ainda predomina, mas não podemos descartar, em hipótese nenhuma, a importância do mesmo, mas enfatizamos a necessidade de ocorrerem mudanças que se ajustem ao novo perfil de aluno e de mundo. Ao mencionarmos a teoria da Complexidade de Morin, sugerimos uma perspectiva de mundo mais ampla, que seja capaz de atender o todo em suas partes.

\section{Referências}

ANTUNES, Ângela. Leitura do Mundo no Contexto da Planetização: Por uma pedagogia da sustentabilidade. Tese (Doutorado) - Universidade de São Paulo, Faculdade de Educação. São Paulo.

BACHA, Maria de Lourdes Considerações teóricas sobre o conceito de

Sustentabilidade. Trabalho apresentado no VII Simpósio de Excelência em Gestão e Tecnologia, 2010. Disponível em:

<http://www.aedb.br/seget/artigos10/31_cons\%20 teor\%20bacha.pdf>. Acesso em: 13 nov. 2012.

BRASIL. Secretaria da Educação Fundamental. Parâmetros curriculares nacionais: terceiro e quarto ciclos do ensino fundamental: temas transversais. Brasília: MEC/SEF, 1998, 436p. 
DUMONT, Alberto Santos. O que eu vi e o que nós veremos. São Paulo: Hedra, 1918.

FREIRE, Paulo. Educação e Atualidade Brasileira. Recife: Universidade Federal do Recife, 1959.

GADOTTI, Moacir . Boniteza de um sonho: ensinar e aprender com sentido. Novo Hamburgo. FEEVALE, 2003. 79p.

GOLDSMITH, E., et al. Blueprint for survival. Boston: Penguin, Harmondsworth \& Houghton Mifflin, 1972.

GRANDISOLI, Edson. Educação para a sustentabilidade. (2011). Disponível em: http://envolverde.com.br/educacao/sociedade-educacao/educacao-para-asustentabilidade/ Acesso em 20/10/2012

LAYRARGUES, Philippe Pomier. Para que a Educação Ambiental encontre a educação. In: LOUREIRO, Carlos Frederico B. Trajetória e Fundamentos da educação ambiental. São Paulo: Cortez, 2004, p.11-18.

MOREIRA, Antonio Flávio Barbosa; CANDAU, Vera Maria. Currículo, conhecimento e cultura. In: MOREIRA, Antonio Flávio e ARROYO, Miguel. Indagações sobre currículo. Brasília: Departamento de Políticas de Educação Infantil e Ensino Fundamental. p. 83-111.

MORIN, Edgar. Introdução ao Pensamento Complexo. Lisboa, Instituto Piaget, 1991. . Os sete saberes necessários à educação do futuro. 8. ed. São

Paulo: Cortez, 2000.

PRONK, J.; UL HAQ, M. Sustainable development: from concept to action. The Hague Report. New York: United Nations Development Programme, 1992.

QUAREMA, Adilene Gonçalves. A pedagogia e o currículo para a educação do trabalho. Rio de Janeiro: Anped, 2004.

SANTOS, Edvalter Souza. Educação e sustentabilidade. Educação e Contemporaneidade, Salvador, v. 11, n. 18, p. 259-279, jul./dez. 2002.

SILVA, Tomaz Tadeu da. Currículo e identidade social: territórios contestados. In: SILVA, Tomaz Tadeu da (Org.). Alienígenas na sala de aula. Petrópolis: Vozes, 1995. p. 190-207.

VASCONCELOS, Eduardo Mourão. Complexidade e pesquisa interdisciplinar: epistemologia e metodologia operativa. Petrópolis: Vozes, 2002. 